\title{
Hypertension, poor glycemic control, and microalbuminuria in Cuban Americans with type 2 diabetes
}

This article was published in the following Dove Press journal: International Journal of Nephrology and Renovascular Disease 3 March 20II

Number of times this article has been viewed

\section{Gustavo G Zarini' \\ Joel C Exebio' \\ Deva Gundupalli' \\ Subrata $\mathrm{Nath}^{2}$ \\ Fatma G Huffman'}

'Florida International University, Robert R Stempel School of Public Health, Department of Dietetics and Nutrition, Miami, Florida, USA; ${ }^{2}$ Department of Medicine, University of Texas Health Science Center at San Antonio, San Antonio, Texas, USA
Correspondence: Fatma G Huffman Florida International University, Robert R Stempel School of Public Health,

Department of Dietetics and Nutrition, I I 200 SW, 8th St, HLS-I 450, Miami,

FL 33199, USA

$\mathrm{Tel}+\mathrm{I}$ (305) 348-3788

$\mathrm{Fax}+\mathrm{I}(305)$ 348-1996

Email huffmanf@fiu.edu
Purpose: To investigate to what degree the presence of hypertension (HTN) and poor glycemic control (GC) influences the likelihood of having microalbuminuria (MAU) among Cuban Americans with type 2 diabetes (T2D).

Methods: A cross-sectional study conducted in Cuban Americans $(n=179)$ with T2D. Participants were recruited from a randomly generated mailing list purchased from KnowledgeBase Marketing, Inc. Blood pressure (BP) was measured twice and averaged using an adult size cuff. Glycosylated hemoglobin (A1c) levels were measured from whole blood samples with the Roche Tina-quant method. First morning urine samples were collected from each participant to determine MAU by a semiquantitative assay (ImmunoDip).

Results: MAU was present in 26\% of Cuban Americans with T2D. A significantly higher percentage of subjects with MA had HTN $(P=0.038)$ and elevated A1C $(P=0.002)$ than those with normoalbuminuria. Logistic regression analysis showed that after controlling for covariates, subjects with poor GC were 6.76 times more likely to have MAU if they had hypertension compared with those without hypertension ( $P=0.004 ; 95 \%$ confidence interval $[\mathrm{CI}]: 1.83,23.05)$.

Conclusion: The clinical significance of these findings emphasizes the early detection of MAU in this Hispanic subgroup combined with BP and good GC, which are fundamentals in preventing and treating diabetes complications and improving individuals' renal and cardiovascular outcomes.

Keywords: blood pressure, A1c, kidney function, cardiovascular disease, Hispanics

\section{Introduction}

In past years, numerous studies have described the role of microalbuminuria (MAU) as a predictor of cardiovascular disease (CVD) and death among subjects with type 2 diabetes (T2D). ${ }^{1-3}$ MAU is one of the earliest clinical signs for diabetic nephropathy and a significant risk factor for progression to proteinuria. ${ }^{1}$ Additionally, hypertensive T2D individuals with MAU have an increased risk of developing endstage renal disease (ESRD). ${ }^{4}$ Risk factors known to be associated with CVD and diabetic nephropathy are high blood pressure (BP) and elevated glycosylated hemoglobin (A1c). 5 Achieving adequate BP and glycemic control (GC) plays an essential role in preventing renal and CVD events in individuals with T2D.

A current secondary analysis from the Hispanic Health and Nutritional Examination Survey (HHANES) ${ }^{7}$ indicated that Cuban Americans have higher serum cholesterol and systolic BP than Puerto Ricans and Mexican Americans. Furthermore, compared with other Hispanic subgroups, Cuban Americans have the highest proportion of hypertension (HTN) and mean serum creatinine levels. ${ }^{8}$ Smith and Barnett ${ }^{9}$ examined 
the National Center for Health Statistics (NCHS) from 1996 to 1997 and concluded that Cuban Americans 35 years of age and older have the highest percentage of diabetes-related deaths compared with other Hispanics.

Although previous studies have shown significant differences and diversity within Hispanics, further studies conducted in the Cuban American population are scarce. Over the past decade, the prevalence of T2D has increased, especially among Cuban Americans who have a higher incidence of diabetes $(8.2 \%)$ compared with $6.6 \%$ of non-Hispanic Whites. ${ }^{10}$ The high incidence of T2D combined with an increased risk for developing diabetes complications warrants further examination of the Cuban American population. Screening for MAU can detect individuals at risk for renal dysfunction and CVD events and possibly reduce the burden associated with diabetes complications. Therefore, the purpose of this study was to investigate to what degree the coexistence of HTN and poor GC influences the likelihood of having MAU among Cuban Americans with T2D. It was hypothesized that individuals with T2D, HTN, and poor GC will have an increased likelihood to test positive for MAU. It was further hypothesized that this association will be stronger after controlling for confounding variables.

\section{Methods}

\section{Design}

This was a cross-sectional study conducted in Cuban Americans with and without T2D.

\section{Study population}

Data from a complete sample set of Cuban Americans with and without T2D were used in the present study. Recruitment of participants was conducted in alternate phases of potential subjects with and without T2D, age matching subjects by age groups. During a 1-year period, approximately 10,000 letters outlining the study were mailed to subjects aged 30 years or older with and without diabetes. Letters were sent in English and Spanish and included an invitation flyer to which interested participants could respond. The participants were initially recruited by random selection (every tenth address) from a randomly generated mailing list. The list of addresses was purchased from KnowledgeBase Marketing, Inc., Richardson, TX, USA. This company provided a mailing list of Cuban Americans identified as with and without T2D from Miami-Dade and Broward Counties, Florida. Three percent $(n=300)$ of the letters were returned due to unknown addresses. From the remaining delivered mail, 4\% $(n=388)$ responded. Interested participants were initially interviewed on the phone, at which time the study purpose was explained and the age and gender of the responders were determined. To ascertain T2D status, each participant was asked for the age of diagnosis and initial treatment modalities. Only 18 subjects did not qualify for the study for not being Cuban Americans $(n=2)$, age younger than 30 years $(n=9)$, and having other chronic illnesses $(n=7)$. If a subject was determined to be eligible, then their participation was requested at the Human Nutrition Laboratory at Florida International University (FIU). Participants were instructed to refrain from smoking, consuming any food and beverages except water, and doing any unusual exercise for at least 8 hours prior to their blood collection. Subjects with T2D were matched for age and gender with subjects without diabetes. This study was approved by the Institutional Review Board at FIU. The purpose and protocol of the study were explained to the subjects, and their written consent, either in Spanish or English, was obtained prior to the commencement of the study. Seven participants reported not having diabetes but were reclassified because their lab results classified them as having T2D according to American Diabetes Association (ADA) standards. These subjects were given their laboratory results and referred to their physicians. For the data analysis, subjects with caloric intakes $>5000$ kcals $(n=2)$ and missing A1c levels $(n=2)$ were excluded. For two participants, we were unable to perform A1c analysis. In total, we included only the data from subjects with T2D $(n=179)$ who were aged 30 years and older.

\section{Study variables}

A sociodemographic questionnaire was given to each participant to complete, which included questions related to age, gender, smoking status, medications for diabetes, HTN, and cholesterol. Height and weight were measured using a Seca balance scale (Seca Corp, Columbia, MD, USA). Body mass index (BMI) was calculated as weight in $\mathrm{kg} / \mathrm{height}$ in $\mathrm{m}^{2}$. BP was measured twice then averaged in participants in a sitting position after a 15 -minute rest using a random zero sphygmomanometer (Tycos 5090-02 Welch Allyn Pocket Aneroid Sphygmomanometer, Arden, NC, USA) and a stethoscope (Littmann Cardiology, 3M, St Paul, MN, USA). HTN was defined as follows: systolic BP $\geq 140 \mathrm{~mm} \mathrm{Hg}$ systolic or diastolic $\mathrm{BP} \geq 90 \mathrm{~mm} \mathrm{Hg}$ or using antihypertensive treatment. $^{11}$

\section{Dietary assessment}

Dietary intake was measured using a validated semiquantitative food frequency questionnaire (FFQ) developed by 
Willett et al. ${ }^{12}$ This FFQ has also been validated by Nath and Huffman ${ }^{13}$ exclusively for the Cuban American population. Participants self-reported average consumption of specified amounts of various foods over the past year and chose from frequency responses ranging from "never" to "six or more servings per day". In addition to food items, the FFQ included questions about type and duration of vitamin/mineral supplement use, alcohol consumption, and specific details about fat, salt, and sugar used in cooking and as condiments. Macro- and micronutrient intake was calculated by multiplying frequency of consumption by the nutrient value of the food item obtained from the Harvard University Food Composition Database (Boston, MA, USA).

\section{Blood collection}

Venous blood $(20 \mathrm{~mL})$ was collected from each subject after an overnight fast (at least 8 hours) by a certified phlebotomist using standard laboratory techniques. Blood samples were collected into a Vacutainer ${ }^{\circledR}$ Serum Separator Tube (SST) (Becton, Dickinson and Company, Franklin Lakes, NJ) for analysis of lipids and another tube containing ethylenediamine tetraacetic acid to analyze A1c. After coagulation was completed (30-45 minutes), the SST was centrifuged at 2500 RPM for 30 minutes. Lipid panel was assayed by enzymatic methods, and A1c percentages were measured from whole blood samples with the Roche Tinaquant method by Laboratory Corporation of America, Miami, FL, USA (LabCorp $\left.{ }^{\circledR}\right)$. Poor GC was defined according to the ADA standards $(\mathrm{A} 1 \mathrm{c}>7 \%) .{ }^{14}$

\section{Urinary albumin}

Fresh, single-voided, first morning urine samples were collected from each participant to determine MAU by a semiquantitative assay (ImmunoDip, Diagnostic Chemicals Limited, Oxford, CT, USA). ImmunoDip Urinary Albumin Test uses a monoclonal antibody against human serum albumin to detect MAU. The study conducted by Davidson et $\mathrm{al}^{15}$ was designed to evaluate the clinical performance of the ImmunoDip dipstick compared with a reference measure recommended by the ADA for detecting MAU (albumin:creatinine ratio $<30 \mathrm{ug} / \mathrm{mg}$ [negative]; $>30 \mathrm{ug} / \mathrm{mg}$ [positive]) determined by laboratory techniques (Quest Hitachi 717 autoanalyzer). Additionally, results from the ImmunoDip were compared with quantitatively measured albumin concentrations as a secondary outcome. Urinary albumin concentrations were considered $<18 \mathrm{mg} / \mathrm{L}$ (negative) and $>18 \mathrm{mg} / \mathrm{L}$ (positive). Screening for MAU with ImmunoDip exhibited a sensitivity of $96 \%$ and specificity of $80 \%$ when compared with albumin:creatinine ratio $>30 \mathrm{ug} / \mathrm{mg}$.
When ImmunoDip was examined against quantitatively measured albumin concentrations, the dipstick yielded a sensitivity of $95 \%$ and specificity of $94 \%$. Recommendations from the National Academy of Clinical Biochemistry (NACB) for the diagnosis and management of diabetes indicated that a useful semiquantitative screening test for MAU should have a sensitivity $>95 \% .{ }^{16}$ The ImmunoDip dipstick fulfilled the requirements from the NACB as a screening tool to detect MAU. In our study, positive for MAU was defined as urinary albumin concentrations of $>18 \mathrm{mg} / \mathrm{L}$ in spot collection. This cut-off value was established by the manufacturer (ImmunoDip, Diagnostic Chemicals Ltd) and corresponded to albumin:creatinine ratio $>30 \mathrm{ug} / \mathrm{mg}$ values for MAU detection. ${ }^{15}$

\section{Data analysis}

All analyses were performed using SPSS Version 17 (SPSS Inc., Chicago, IL, USA). T-tests and Chi-square tests were performed to compare means and proportion differences between subjects with and without MAU. Unadjusted odds ratios and logistic regression analysis were conducted to investigate the extent to which HTN and GC are associated with an increased likelihood of having MAU. Controlled variables included in the logistic regression analysis were age, gender, BMI, known duration of diabetes, total cholesterol levels, diabetes and cholesterol medications, smoking, total kcal and protein intake, and intake of potassium, phosphorous, and sodium. The level of significance was set at $P<0.05$.

\section{Results}

MAU was present in $26 \%(n=47)$ of Cuban Americans with T2D. There was a significantly higher percentage of subjects with MAU classified as hypertensive $(P=0.038)$ and taking diabetes medication $(P=0.039)$ compared with those without MAU. Additionally, subjects who tested positive for MAU had significantly higher A1c levels $(P=0.002)$ than those with normoalbuminuria (Table 1).

Unadjusted odds ratios indicated that subjects with poor GC were 3.96 times more likely to have positive MAU if they had HTN compared with those without HTN $(P=0.014 ; 95 \%$ confidence interval $[\mathrm{CI}] 1.25,12.5)$ (Figure 1). Logistic regression analysis showed that after controlling for covariates, subjects with poor GC were 6.76 times more likely to have MAU if they had HTN compared with those without HTN $(P=0.004 ; 95 \% \mathrm{CI}$ 1.83, 23.05) (Table 2). 
Table I Characteristics of subjects ${ }^{\mathrm{a}}$

\begin{tabular}{|c|c|c|c|}
\hline & \multicolumn{2}{|c|}{ Cuban Americans with type 2 diabetes } & \multirow[t]{3}{*}{$P$ value } \\
\hline & \multicolumn{2}{|c|}{ Microalbuminuria } & \\
\hline & $\begin{array}{l}\text { Positive } \\
(n=47)\end{array}$ & $\begin{array}{l}\text { Negative } \\
(n=132)\end{array}$ & \\
\hline Gender (female/male) (\%) & $53.2 / 46.8$ & $64.4 / 35.6$ & 0.175 \\
\hline Age (years) & $67.9 \pm 12.9$ & $64.4 \pm 11.4$ & 0.083 \\
\hline Body mass index $\left(\mathrm{kg} / \mathrm{m}^{2}\right)$ & $30.5 \pm 6.0$ & $31.9 \pm 6.7$ & 0.219 \\
\hline Waist circumference $(\mathrm{cm})$ & $105.7 \pm 15.0$ & $105.4 \pm 14.6$ & 0.892 \\
\hline Smoking (\%) & 17.0 & 14.4 & 0.666 \\
\hline Known duration of diabetes (years) & $10.5 \pm 10.1$ & $8.9 \pm 9.5$ & 0.338 \\
\hline Diabetes medications (\%) & 89.4 & 75 & 0.039 \\
\hline Glycosylated hemoglobin (\%) & $8.2 \pm 2.0$ & $7.4 \pm 1.5$ & 0.002 \\
\hline Hypertension medications (\%) & 61.7 & 52.3 & 0.265 \\
\hline Systolic blood pressure (mm Hg) & $133.69 \pm 14.5$ & $|3| .48 \pm 15.6$ & 0.399 \\
\hline Diastolic blood pressure (mm Hg) & $78.3 \pm 9.9$ & $80.1 \pm 8.4$ & 0.225 \\
\hline Hypertension (\%) & 78.7 & 62.1 & 0.038 \\
\hline Cholesterol medications (\%) & 27.7 & 18.9 & 0.209 \\
\hline Total cholesterol (mg/dL) & $188.3 \pm 42.8$ & $196.7 \pm 41.0$ & 0.234 \\
\hline Energy intake (kcal) & $2212.1 \pm 870.0$ & $2165.4 \pm 775.1$ & 0.732 \\
\hline Protein $(g)$ & $108.4 \pm 44.5$ & $105.0 \pm 36.4$ & 0.594 \\
\hline Potassium (mg) & $3676.8 \pm 1436.5$ & $3756.2 \pm 1245.3$ & 0.719 \\
\hline Sodium (mg) & $2208.8 \pm 1091.8$ & $2204.4 \pm 913.5$ & 0.979 \\
\hline Phosphorous (mg) & $1665.7 \pm 688.0$ & $1604.6 \pm 564.2$ & 0.549 \\
\hline
\end{tabular}

Notes: ${ }^{a}$ Data are \% or mean \pm standard deviation. Hypertension was defined as follows: systolic blood pressure (BP) $\geq 140 \mathrm{~mm} \mathrm{Hg}$ systolic or diastolic BP $\geq 90 \mathrm{~mm} \mathrm{Hg}$ or using antihypertensive treatment. $P$ is considered significant at 0.05 .

\section{Discussion}

The results of this study showed that HTN and poor GC are major contributors to increasing the likelihood of having MAU among Cuban Americans with T2D. The combination and/or interaction of these factors over time might increase the risk for progression to proteinuria/ESRD and CVD in this population. Our findings are supported by the multicenter study conducted in Europe that found that the likelihood of having MAU increases in patients when HTN and poor GC are present along with other coexisting risk factors for CVD. ${ }^{17}$ Ravid et $\mathrm{al}^{5}$ reported from their longitudinal study that a

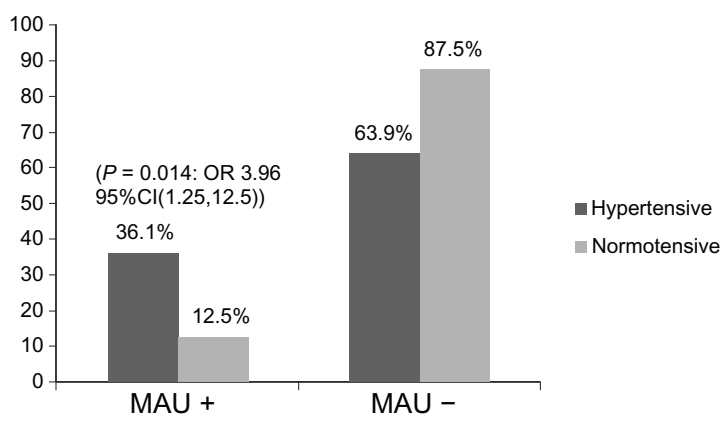

Figure I Unadjusted odds ratios (OR) for microalbuminuria (MAU) among hypertensive Cuban Americans with poor glycemic control. ${ }^{a}$ Note: ${ }^{a} P$ is considered significant at 0.05 . combination of risk factors, including abnormal BP, plasma cholesterol, A1c levels, high BMI, and male gender, identifies a group of individuals for poor renal and cardiovascular outcomes.

Maintaining adequate BP and GC is an important therapeutic goal among individuals with T2D. The UK Prospective Diabetes Study (UKPDS), ${ }^{18}$ a longitudinal study with a 10-year median follow-up, showed that exposure over time to hyperglycemia was associated with diabetes complications in subjects with T2D. This study also indicated that for every $1 \%$ reduction in $\mathrm{A} 1 \mathrm{c}$ level, the risk for microvascular complications decreased by $37 \%$ and diabetes-related death by $21 \%$. A study by Thomaseth et $\mathrm{al}^{19}$ showed that in

Table 2 Likelihood of having microalbuminuria among Cuban Americans with poor glycemic control ${ }^{a}$

\begin{tabular}{llll}
\hline Parameter & OR & $\mathbf{9 5 \%} \mathbf{C l}$ for OR & P value \\
\hline Hypertensive & 6.76 & 1.83 to 25.01 & 0.004 \\
Normotensive & 1.08 & 0.30 to 3.93 & 0.899 \\
\hline
\end{tabular}

Notes: ${ }^{a}$ Hypertension by glycemic control interaction $X^{2}(I, n=179)=4.05$, $P=0.044$. Controlled variables included in the logistic regression analysis were age, gender, body mass index, known duration of diabetes, total cholesterol levels, diabetes and cholesterol medications, smoking, total kcal and protein intakes, and intakes of potassium, phosphorous, and sodium. $P$ is considered significant at 0.05 . Abbreviations: $\mathrm{Cl}$, confidence interval; OR, odds ratio. 
hypertensive T2D subjects with incipient diabetic nephropathy, both tight BP control and optimal GC delay the progression of glomerular filtration rate deterioration. Additionally, hypertensive individuals with T2D under tight BP control experience a reduction in risk for microvascular and macrovascular complications. ${ }^{20}$

The mechanism and pathways involving MAU with diabetic nephropathy and CVD are not fully understood. They may be interrelated with endothelial dysfunction and inflammation. ${ }^{21}$ Stehouwer et $\mathrm{al}^{22}$ examined the relationship between endothelial dysfunction and inflammation with MAU and risk of death in a prospective study among subjects with T2D. The results of that study showed that those participants with MAU, endothelial dysfunction, and inflammation had an increased risk in mortality; however, the associations of these variables with risk of mortality were independent from each other. Hyperglycemia and obesity were associated with an increase in markers of endothelial dysfunction and inflammation activity, ${ }^{22}$ possibly indicating that the combinations of these factors may be interrelated in increasing the risk of death.

The usual course of MAU is progressive; however, not all T2D individuals with MAU will develop macroalbuminuria. Several authors have documented remission and/or regression of MAU in subjects with T2D. ${ }^{23-27}$ Antihypertensive therapy has been shown to reduce or slow the progression of diabetic nephropathy. In a 6-year prospective study, remission and regression to normoalbuminuria were observed in about $50 \%$ of T2D individuals. ${ }^{23}$ Other factors independently linked with remission and/or regression of MAU were proper BP and GC and short duration of MAU. The study by Chan et $\mathrm{al}^{24}$ with a 5-year mean follow-up of T2D patients with MAU treated with angiotensin-converting enzyme (ACE) inhibitor medications showed a $13 \%$ reduction in urinary albumin excretion (UAE). In addition, the authors pointed out the main role that BP and GC play in renal function. $\mathrm{T} 2 \mathrm{D}$ individuals treated with angiotensin receptor blockers (ARBs) (eg, irbesartan and valsatran) experienced a $38 \%$ and $44 \%$ reduction in UAE over 2-year and 6-month follow-ups, respectively. ${ }^{25,26}$ Evidence from another prospective study with a 7.8-year follow-up indicated that $30 \%$ of the participants on antihypertensive therapy achieved remission to normoalbuminuria. ${ }^{27}$ Additionally, the odds for remission to normoalbuminuria increased in these participants with every $1 \%$ decrease in A1c level. Furthermore, in a study conducted by Mogensen et al, ${ }^{28}$ urinary albumin:creatinine ratio was decreased by $50 \%$ after a 3-month combination treatment with ARB and ACE inhibitors in hypertensive T2D individuals with MAU. Remission and/or regression of MAU may not only conserve renal function but also reduce the risk of CVD.

MAU is one of the earliest clinical signs of renal impairment. Testing for MAU has been recommended by the ADA in individuals with T2D to be performed at diagnosis of diabetes and every year afterwards. ${ }^{29}$ The ImmunoDip dipstick is a rapid and easy screening test to perform, does not involve equipment and/or skilled personnel, exhibits a high sensitivity, requires only a random urine sample (first morning urine is recommended), and has a relatively low cost. However, this test does not quantify urinary albumin values and requires confirmation with a secondary analysis. This method can be used in a physician's office and/or research setting as a first screening tool to detect the presence of MAU. The clinical significance of early screening and monitoring for MAU is possibly to improve individuals' prognosis for microvascular and macrovascular complications, especially among T2D individuals with other concomitant conditions.

\section{Limitations of the study}

First, due to the cross-sectional design of the study, singlevoided urine was collected to measure MAU, and we were not able to determine the cause-effect relationship between the variables. Second, due to the relatively small sample size in this study, our sample of Cuban Americans with T2D is not representative of the entire Cuban American population living in the USA. Nevertheless, to our knowledge, this is the first and only study that has examined the relationship between MAU, HTN, and GC in this Hispanic subgroup, which has an increased risk for T2D and CVD.

\section{Conclusion}

Early detection of MAU in this population may provide more valuable treatment and improve individuals' renal and CVD outcomes. The therapeutic goals and strategies for MAU should focus on preventing long-term complications associated with T2D, such as kidney and heart diseases. Further investigations need to be carried out to fully understand the mechanism and absolute CVD risk that an individual with T2D has when MAU coexists with other comorbidities.

\section{Acknowledgment}

This research was funded by a grant from NIH/MBRS/ SCOREAC\#124401529/42 to the corresponding author. 


\section{Disclosure}

The authors report no conflicts of interest in this work.

\section{References}

1. Mogensen CE. Microalbuminuria predicts clinical proteinuria and early mortality in maturity-onset diabetes. $N$ Engl J Med. 1984;310(6): 356-360.

2. Dinneen SF, Gerstein HC. The association of microalbuminuria and mortality in non-insulin-dependent diabetes mellitus. A systematic overview of the literature. Arch Intern Med. 1997;157(13):1413-1418.

3. Valmadrid CT, Klein R, Moss SE, Klein BE. The risk of cardiovascular disease mortality associated with microalbuminuria and gross proteinuria in persons with older-onset diabetes mellitus. Arch Intern Med. 2000;160(8):1093-1100.

4. Ismail N, Becker B, Strzelczyk P, Ritz E. Renal disease and hypertension in non-insulin-dependent diabetes mellitus. Kidney Int. 1999;55(1):1-28.

5. Ravid M, Brosh D, Ravid-Safran D, et al. Main risk factors for nephropathy in type 2 diabetes mellitus are plasma cholesterol levels, mean blood pressure, and hyperglycemia. Arch Intern Med. 1998;158(9):998-1004.

6. Park JY, Kim HK, Chung YE, et al. Incidence and determinants of microalbuminuria in Koreans with type 2 diabetes. Diabetes Care. 1998;21(4):530-534.

7. Aponte J. Diabetes-related risk factors across Hispanic subgroups in the Hispanic health and nutritional examination survey (1982-1984). Public Health Nurs. 2009;1:23-38.

8. Rodriguez RA, Hernandez GT, O'Hare AM, et al. Creatinine levels among Mexican Americans, Puerto Ricans, and Cuban Americans in the Hispanic Health and Nutrition Examination Survey. Kidney Int. 2004;66(6):2368-2373.

9. Smith CA, Barnett E. Diabetes-related mortality among Mexican Americans, Puerto Ricans, and Cuban Americans in the United States. Rev Panam Salud Publica. 2005;18(6):381-387.

10. Centers for Disease Control and Prevention: 2007 National Diabetes Fact Sheet. http://www.cdc.gov/diabetes/pubs/estimates07.htm\#4. Accessed October 5, 2010.

11. National High Blood Pressure Education Program Coordinating Committee. The Seventh Report of the Joint National Committee on Prevention, Detection, Evaluation, and Treatment of High Blood Pressure: the JNC 7 report. J Am Med Assoc. 2003;289(19):2560-2572.

12. Willett WC, Sampson L, Stampfer MJ, et al. Reproducibility and validity of a semiquantitative food frequency questionnaire. Am J Epidemiol. $1985 ; 122: 51-65$.

13. Nath SD, Huffman FG. Validation of a semiquantitative food frequency questionnaire to assess energy and macronutrient intakes of Cuban Americans. Int J Food Sci Nutr. 2005;56:309-314.

14. American Diabetes Association. Standards of medical care in diabetes: 2010. Diabetes Care. 2010;33 Suppl 1:S11-S61.

15. Davidson MB, Bazargan M, Bakris G, et al. ImmunoDip: an improved screening method for microalbuminuria. Am J Nephrol. 2004;24(3): $284-288$.
16. Sacks DB, Bruns DE, Goldstein DE, et al. Guidelines and recommendations for laboratory analysis in the diagnosis and management of diabetes mellitus. Clin Chem. 2002;48(3):436-472.

17. Rossi MC, Nicolucci A, Pellegrini F, et al. Identifying patients with type 2 diabetes at high risk of microalbuminuria: results of the DEMAUND (Developing Education on Microalbuminuria for Awareness of reNal and cardiovascular risk in Diabetes) Study. Nephrol Dial Transplant. 2008;23(4):1278-1284.

18. Stratton IM, Adler AI, Neil HA, et al. Association of glycaemia with macrovascular and microvascular complications of type 2 diabetes (UKPDS 35): prospective observational study. Br Med J. 2000; 321(7258):405-412.

19. Thomaseth K, Pacini G, Morelli P, et al. Importance of glycemic control on the course of glomerular filtration rate in type 2 diabetes with hypertension and microalbuminuria under tight blood pressure control Nutr Metab Cardiovasc Dis. 2008;18(9):632-638.

20. UK Prospective Diabetes Study Group. Tight blood pressure control and risk of macrovascular and microvascular complications in type 2 diabetes: UKPDS 38. UK Prospective Diabetes Study Group. Br Med J. 1998; 317(7160):703-713.

21. Persson F, Rossing P, Hovind P, et al. Endothelial dysfunction and inflammation predict development of diabetic nephropathy in the Irbesartan in Patients with Type 2 Diabetes and Microalbuminuria (IRMAU 2) study. Scand J Clin Lab Invest. 2008;68(8):731-738.

22. Stehouwer CD, Gall MAU, Twisk JW, et al. Increased urinary albumin excretion, endothelial dysfunction, and chronic low-grade inflammation in type 2 diabetes: progressive, interrelated, and independently associated with risk of death. Diabetes. 2002;51(4):1157-1165.

23. Araki S, Haneda M, Sugimoto T, et al. Factors associated with frequent remission of microalbuminuria in patients with type 2 diabetes. Diabetes. 2005;54(10):2983-2987.

24. Chan JC, Ko GT, Leung DH, et al. Long-term effects of angiotensinconverting enzyme inhibition and metabolic control in hypertensive type 2 diabetic patients. Kidney Int. 2000;57(2):590-600.

25. Parving HH, Lehnert H, Bröchner-Mortensen J, et al. Irbesartan in Patients with Type 2 Diabetes and Microalbuminuria Study Group. Long-term effects of angiotensin-converting enzyme inhibition and metabolic control in hypertensive type 2 diabetic patients. NEngl J Med. 2001;345(12):870-878.

26. Viberti G, Wheeldon NM. Microalbuminuria reduction with valsartan in patients with type 2 diabetes mellitus: a blood pressure-independent effect. Circulation. 2002;106(6):672-678.

27. Gaede P, Tarnow L, Vedel P, et al. Remission to normoalbuminuria during multifactorial treatment preserves kidney function in patients with type 2 diabetes and microalbuminuria. Nephrol Dial Transplant. 2004;19(11):2784-2788.

28. Mogensen CE, Neldam S, Tikkanen I, et al. Randomised controlled trial of dual blockade of renin-angiotensin system in patients with hypertension, microalbuminuria, and non-insulin dependent diabetes: the candesartan and lisinopril microalbuminuria (CALM) study. $\mathrm{Br}$ Med J. 2000;321:1440-1444.

29. American Diabetes Association. Standards of medical care in diabetes: 2009. Diabetes Care. 2009;32 Suppl 1:S13-S61.

\section{Publish your work in this journal}

The International Journal of Nephrology and Renovascular Disease is an international, peer-reviewed open-access journal focusing on the pathophysiology of the kidney and vascular supply. Epidemiology, screening, diagnosis, and treatment interventions are covered as well as basic science, biochemical and immunological studies. The journal welcomes original research, clinical studies, reviews \& evaluations, expert opinion and commentary, case reports and extended reports. The manuscript management system is completely online and includes a very quick and fair peerreview system, which is all easy to use. Visit http://www.dovepress.com/ testimonials.php to read real quotes from published authors. 